\title{
Calendar Anomalies In Kuwait Stock Exchange: Anomalous Evidence
}

\author{
Turki Alshimmiri, (Email: dari@kuc01.kuniv.edu.kw), Kuwait University, Kuwait
}

\begin{abstract}
Calendar anomalies such as January and weekend effects were found to exist in many international stock markets. Explanations of these anomalies are vast and so far are not robust. This paper examines these anomalies in a distinct emerging market, Kuwait stock market (KSE). With Kuwait joining the World Trade Organization treaty (WTO) and by opening its stock market to foreign investors, it becomes important to investigate stock behavior in KSE. The study finds interesting regularities in trading patterns of investors related to the weekend as well as to the day of the week. That is, there exists a weekend effect and is robust to the methodology applied. However, this effect is different from that uncovered in other developed stock markets in the sense that the first trading day (Saturday in KSE) shows positive returns and the second trading day (Sunday in KSE) shows negative returns. Other days show no systematic behavior and if detected, it is insignificant. On the other hand, January effect is not detected in KSE and returns in January are mot different from those in other months. However, returns during summer months (MaySeptember) tend to be significantly higher than returns during other months of the year (OctoberApril) in what is termed as summer effect. The most plausible elucidation relates to human factors as investors in KSE sense no unhealthy information about firms over the weekend and hence make their portfolio acquisition decisions in Saturdays and reverse these decisions on next day to capitalize on their marginal profits.
\end{abstract}

\section{Introduction}

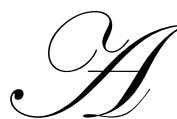

nomalous regularities in security returns have been analyzed for a long time as they represent a great challenge for the equilibrium theories of asset returns. Besides anomalies that are related to firm characteristics such as the size anomaly of Banz (1981) and Reinganum (1981), there is a body of literature that tackles peculiar patterns labeled as calendar (or seasonal) anomalies as rates of returns behave differently and consistently in certain times of the year. From these is the weekend effect where stock returns are found to be significantly negative in the first trading day (Monday) as documented by Cross (1973), French (1980), Gibbons and Hess (1981), Keim and Stambaugh (1984), Ball and Bowers (1986), to name a few. In addition to Monday effect, there is also the January effect. Rozeff and Kinney (1976), Tinic and West (1984), Gultekin and Gultekin (1983), among others, all show that expected returns and risk show consistent and reliable relation in January while the exclusion of January returns would result in almost zero risk premium. As in the US, the positive returns in January have also been found in many international stock markets. All these anomalies are considered, by many, as evidence against market efficiency. In spite of the documented literature of the calendar anomalies, the more recent findings interrogate with the previous results, at least in the recent periods. For example, the previously documented predictability of returns was shown to be declining (Lo et al 1997). Agrawal and Tandom (1994) survey many countries and find that Monday effect is absent in the eighties.

Although the anomalies evidence has been well documented for almost all developed stock markets (Jaffe and Westerfield 1989; Agrawal and Tandom 1994), the evidence of anomalies in developing and emerging stock markets is almost rare and ambiguous. As these markets are developing, they are structurally different from developed stock markets. That is, these markets, as they are developing, have different institutional differences relative to the more developed stock markets. For example, while Branch (1977) and Brauer and Chang (1990), among others, bring the tax loss transactions as a valid explanation for the January effect, that elucidation can not be 
applied to all market settings since many markets function in a free-tax economy ${ }^{1}$. In addition to the investment tax structure, other elements include the information-based feature (which mitigates the efficiency of these markets), the institutional infrastructure (markets entry and exit regulations), lack of liquidity and depth, the accounting and legal systems, and the market microstructure elements. This might have its effect on the nature of the seasonal anomalies and hence differences in the mode of the anomalies might arise Based upon that, this study should add to the literature by its possible unique findings regarding either supporting or rejecting both the Monday and the January effects in a unique market setting where the week starts in Saturday and ends in Wednesday and all firms pay no taxes. This the first study for calendar anomalies in KSE which employs clean and reliable data that start from the inception of the KSE in 1984. Therefore, it tends to be more exploratory in nature than analytically with respect to anomaly rational.

\section{Kuwait Stock Market (KSE)}

The properties of Kuwait stock market has been analyzed recently and compared to other international stock markets by many researchers. For example, Butler et al (Journal of Banking and Finance, 1992), examined the efficiency of KSE and document a competitive auction stock exchange system. Al-loughani (1995) also finds that the behavior of the stock returns in KSE, like that in US, is not random walk.

Like most other markets, KSE has gone through many statutory and institutional changes which matched the common "boom-bust" scenarios that occur to any stock market. Three stages have characterized the history of stock trading in Kuwait and each stage usually ends with a crash. The establishment of the official KSE in 1984 after the crash of Almanak (over-the-counter market) has set a new era for stock trading in Kuwait as many regulations were instituted to organize trading. In general, one can fairly say that key traders and insiders have dominated stock trades especially before 1990, when the KSE closed for about two years due to the Iraqi occupation of Kuwait. In addition, throughout its history, KSE has been characterized by irregularity in trades and price formation process. Many ambition efforts by the economic administration of the country are being reflected in clear steps to improve the economy and the investment environment, which eventually should positively influence the efficiency of KSE. For example, recently, Kuwaiti parliament approved a code that permits foreign investors to trade in KSE. This should have its effect on stabilizing the market and enlarge the investors' base $^{2}$. One impediment to improving efficiency of KSE is the regulatory structure of the market. Unlike most developed markets, KSE is supervised by, besides its administration, two ministries (Ministry of Finance and Ministry of Commerce) and the central bank. It has been argued by many investors that these regulatory organizations cause trading noise ${ }^{3}$ by their occasional conflicting commandments, which causes confusion to investors.

\section{Hypothesis Development}

While calendar anomalies have been analyzed in many developed big markets, smaller emerging markets have not yet been analyzed enough. These markets have definitely different settlement procedures, especially delays between trading and settlement. Many standard models in modern finance are ill suited and can not be used (as they are) to deal with the specific circumstances arising continuously in the emerging markets. Hence, trading in emerging markets (such as KSE) provides a vehicle by which many finance models can be modified to accommodate the structure of (and even to develop new models to suit) these markets (Bekaert and Harvey, 2003).

KSE represents a unique market setting in which many internationally-observed calendar anomalies might have different form. First, up to the moments of writing this study, derivative securities are not allowed in KSE and no bond market is actively established. Second, the only traded security is the common stock and no issuance of preferred stocks. Third, a new forward contract has been instituted since February 1998 but trading is valid only for 10 financial firms. In addition, it is not similar to the forward contract available for investors in other markets. Fourth, trading of many firms in the index is nonsynchronous and all firms don't pay taxes. Furthermore, fluctuations in prices seem to be affected by sociopolitical factors. Fifth, as mentioned earlier, and unlike other developed markets, KSE is controlled by three entities besides its administration. Further, firms' annual statements usually delayed for months after the end of the fiscal year given the laxity of regulations that govern trading rules ${ }^{4}$ and even though, all these financial statements are barely informative enough which yields huge noise in trading. 
Sixth, insiders can trade on the special information they posses without any regulation against this investment behavior. All these differences between KSE (as an emerging market) and most stock markets in the world are expected to wield its effects on the elsewhere-observed relationships. Based upon these differences, different form of return seasonal might be detected in KSE. Specifically, the following hypotheses are to be investigated

(H1): Returns in Saturday are negative (the weekend effect).

(H2): Returns in January are, on average, positive (January effect).

(H3): Returns during summer time (May-September) are lower than those during other times of the year (OctoberApril) ("sell in May and go a way" or Halloween Indicator)

\section{Data and Methodology}

This study uses daily closing index values that span the period 1-Feb-1984 to 31-Dec-2000, with total sample daily observations of 3663 . The index used is constructed by the Global Investment House (a prestigious investment firm in Kuwait) and is capitalization weighted index which avoids the bias introduced by value weighted indices. The index includes all firms traded in KSE. Unlike western markets, KSE opens Saturday to Wednesday from 9AM to 12:30PM and closes Thursdays and Fridays. Thursdays trading was abandoned on 1984 and the last trading Thursday was at 23-Aug-1984. Due to discontinuities and to preserve data stability, all Thursday observations (i.e. Thursday returns) during 1984 (only 24 obs) were excluded from the analysis but their values were used to calculate the returns of the following Saturdays.

To account for continuous parameterization, all returns are calculated by taking the log of the previous day's index value divided by today's index value. Table (1) contains summary statistics of the data for three types of indexes. "GI" refers to the general index; "LI" refers to the index of large firms; "SI" refers to the index of smallsize firms (the rational behind using three indices will be explained later on). Also, for the "GI" index, the data was portioned for two periods that represent the obligatory two-year-closure of the stock market due to the occupation of Kuwait by Iraq (a test will be carried out later on to show the statistical validity of this conjecture). As the table indicates, one can note that the mean return over the two distinct periods is different. Before the KSE closure, the mean return is negative as is the case when considering the mean return of the total period analyzed. After the KSE closure, however, the mean return tends to be positive. The same result is supported for the three indices analyzed. For the small index, however, the mean return is positive for both periods. On the other hand, for the week days, it is apparent that the mean return for Saturdays ( $1^{\text {st }}$ trading day of the week) is positive and this is true for the three indices used in this study. However, Sundays' mean return is always negative and this is true with all indices. The higher returns of the small index is justified (principally) by the higher standard deviation. On a different note, return distributions are skewed to the left except when considering the small index while the excess kurtosis is highest for the large index. This finding conforms to the sparse evidence of the literature regarding stock returns' distribution (see for example Black 1986).

Following others (like Keim and Stambuagh 1984 ), this study tests for the weekend effect using the following model:

$\mathrm{R}_{\mathrm{i}}=\mathrm{f}\{\mathrm{D} 1, \mathrm{D} 2, \mathrm{D} 3, \mathrm{D} 4, \mathrm{D} 5 ; \mathrm{e}\}$

Where $R_{i}$ denotes the daily continuous returns. D1-D5 are dummy variables that take the value of "1" for the respective day and "zero" otherwise where "D1" represents Saturdays, "D2" represents Sundays, etc. The "e" is a well-behaved error term.

The regression test is carried out for two distinct periods that are believed to have different results. As pointed out earlier, the separation point is the discontinuities of trading ${ }^{5}$ from $2^{\text {nd }}$ of Aug, 1990 till the reopening of the market at $27^{\text {th }}$ of Sept, 1992. Since there was interruption in trading (more than two years), the two periods might be distinct in terms of the parameters' function; and if so, the results of the analysis would be misleading if all data is considered as one series. This conjecture is tested by employing Chow structural break test. 
Furthermore, a mean test (as employed by most previous studies) will be carried out to test the significance of the weekend effect as well as the January effect.

In addition to that, there is a common belief that most people (including investors) travel in summer and accordingly cash their portfolios before summer time, hence, according to this view, month of May signals a start of a bear market. Because of this, very popular and old market wisdom ("sell in May and go a way") has evolved in some western markets. In this attribute, the state of affairs in Kuwait is not different from that in other countries and it comes in a straight line with the stated conjecture as month of May usually signals a long summer break for people in Kuwait. This assumption is tested by employing a dummy-form regression model.

Table 1: Summary Statistics of the Continuous Returns

\begin{tabular}{|c|c|c|c|c|c|c|}
\hline Index & & Time period & Mean & SD & Skew & Kurt \\
\hline \multirow[t]{8}{*}{ GI } & & All Period & -0.0001 & 0.0092 & -0.2350 & 31.4903 \\
\hline & & Before KSE Closure & -0.0006 & 0.0104 & -0.7805 & 34.5069 \\
\hline & & After KSE Closure & 0.0003 & 0.0081 & 0.7652 & 19.0111 \\
\hline & & Saturday & 0.0012 & 0.0092 & 0.8916 & 7.9399 \\
\hline & All & Sunday & -0.0007 & 0.0089 & 1.2849 & 26.6080 \\
\hline & Period & Monday & -0.0006 & 0.0102 & -4.1410 & 57.4989 \\
\hline & & Tuesday & 0.0000 & 0.0088 & 1.0049 & 14.0314 \\
\hline & & Wednesday & -0.0005 & 0.0085 & 2.0740 & 32.8352 \\
\hline \multirow[t]{8}{*}{ LI } & & All Period & -0.0001 & 0.0125 & -1.7072 & 49.3744 \\
\hline & & Before KSE Closure & -0.0007 & 0.0155 & -2.1252 & 44.6123 \\
\hline & & After KSE Closure & 0.0004 & 0.0096 & 0.4594 & 14.7539 \\
\hline & & Saturday & 0.0015 & 0.0121 & 0.1466 & 17.5920 \\
\hline & All & Sunday & -0.0009 & 0.0126 & -1.0472 & 26.2159 \\
\hline & Period & Monday & -0.0010 & 0.0147 & -6.3958 & 90.1963 \\
\hline & & Tuesday & 0.0002 & 0.0112 & 1.1519 & 11.9976 \\
\hline & & Wednesday & -0.0004 & 0.0116 & 2.4647 & 34.3278 \\
\hline \multirow[t]{8}{*}{ SI } & & All Period & 0.0003 & 0.0099 & 0.7211 & 24.4445 \\
\hline & & Before KSE Closure & 0.0001 & 0.0094 & 1.8066 & 43.1500 \\
\hline & & After KSE Closure & 0.0005 & 0.0103 & 0.0662 & 14.1870 \\
\hline & & Saturday & 0.0008 & 0.0114 & 1.0804 & 29.0546 \\
\hline & All & Sunday & -0.0001 & 0.0096 & 0.1721 & 15.3109 \\
\hline & Period & Monday & 0.0003 & 0.0089 & 0.1788 & 13.6627 \\
\hline & & Tuesday & 0.0005 & 0.0101 & 1.3383 & 36.8057 \\
\hline & & Wednesday & 0.0002 & 0.0093 & 0.2478 & 11.6091 \\
\hline
\end{tabular}


The detection of a calendar anomaly might be affected by the method used to construct the index and to some extent, may be affected by the size of firms. Also, there might be an influence on the results due to other phenomena such as nonsychronous trading (usually a trait of many stocks in emerging markets). Therefore, in order to test the sensitivity of results to these assumptions, and in order to test the consistency of the observed regularities, two portfolio indices are used. The first index represents the performance of the largest firms in KSE (top 10 firms in terms of market value) and the second index represents the performance of the smallest firms (lowest 10 firms in terms of market value) in KSE. The size indices (portfolios) are formed at the beginning of each month based on the firms' market values and held for one month. In their study in 1976, Rozeff and Kinney provide intertemporalinformation explanation for the unusual large returns in January which results in positive price reactions to news in January. A complementary argument comes from Barry and Brown in 1985 as their models show higher systematic risk for relatively information-poor securities than that of information-rich securities. One way to test this conjecture is to assume that small-capitalization stocks are poor-information stocks while rich-information stocks are largecapitalization stocks. Another reasoning comes from the fact that the large index used in this study represents the most actively-traded stocks which should mitigate problems associated with the nonsynchronous trading. Consequently, all tests in this study will be carried out by using the three indices. In addition to that, the weekend anomaly will be tested in several ways to check the robustness of the results.

\section{Results and Analysis}

\section{Weekend Effect}

Table (2) contains a mean test (used by many like French, 1980 and Gibbon and Hess, 1981) for the daily returns of the three indices employed in this study. The rational behind stratifying the daily returns into two distinct periods is the mandatory closure of KSE for more than two years. As panel (A) in table (1) shows, there seems to be a consistent weekend effect as the first trading day has significant positive returns for the three indices used. This contradicts the sparse evidence found in all previous studies that first trading day's returns are, on average, significantly negative. Also, the second trading day (Sunday) seems to consistently show significant negative returns for both the large and the general indices but not for the small index. Other daily returns shows no consistency (i.e. third trading day, Monday, returns show negative trend but only when considering large index).

Panels (B) and (C) in table (2) partition the study period into two sub-periods. Panel (B) shows the results of the mean test for the pre-closure period returns. One can observe that the positive returns in Saturday are insignificant in this period even when considering all the indices. However, the mean test shows that Sunday returns are still negative except when considering the small firm index. Monday also has negative returns except when considering the small firm index. Other days show also negative returns but these are insignificant. Panel (C) shows different pattern in the after-closure period as only Saturday returns are significantly positive for all indices. Although other days' returns are negative, they are not different from zero.

As far as the significant results in table (2) are concerned, it seems that large portfolio returns are higher in magnitude than those of the small portfolio. This is true for Saturday returns and for both "GI" and "LI" stocks. However, for Sunday returns, large portfolio returns seem to be more negative.

The inconsistencies in mean tests over the different periods call for more robust analysis. Hence, a regression model is employed to test the weekend effect. Table (3) includes the results of that test. As it appears, results in table (3) confirm the existence of the weekend effect. However, this effect is different than what was established in all previous studies conducted in other international stock markets. While the first day of the week exhibits negative returns in all markets studied so far, astonishingly, the first day of the week in KSE exhibits positive returns. This finding is statistically significant and consistent over the three indices used in this study. In addition, the results show that returns of the second trading day (Sunday) are, on average, negative. This result holds true for the general index as well as for the large firms' index but not for the small firms' index. Monday returns are also negative but significant only when employing the large firms' index. All other daily returns are statistically insignificant and hence are not different from zero. One important feature of the regression results that is worth to mention is that Saturday returns are the highest while Sunday returns are the lowest. 
Table 2: Daily Mean Returns

\begin{tabular}{|c|c|c|c|c|c|}
\hline & Sat & Sun & Mon & Tue & Wed \\
\hline & \multicolumn{5}{|c|}{ Panel (A): All Period } \\
\hline GI & $\begin{array}{l}.12 \\
(.0004)\end{array}$ & $\begin{array}{l}-.07 \\
(.0353)\end{array}$ & $\begin{array}{l}.06 \\
(.1084)\end{array}$ & $\begin{array}{l}.03 \\
(.9245)\end{array}$ & $\begin{array}{l}.04 \\
(.1414)\end{array}$ \\
\hline LI & $\begin{array}{l}.15 \\
(.0008)\end{array}$ & $\begin{array}{l}-.09 \\
.0525)\end{array}$ & $\begin{array}{l}-.1 \\
(.0571)\end{array}$ & $\begin{array}{l}.02 \\
.(5792)\end{array}$ & $\begin{array}{l}-.04 \\
(.3971)\end{array}$ \\
\hline \multirow[t]{2}{*}{ SI } & $\begin{array}{l}.08 \\
(.0531)\end{array}$ & $\begin{array}{l}-.01 \\
(.7781)\end{array}$ & $\begin{array}{l}.03 \\
(.2958)\end{array}$ & $\begin{array}{l}.05 \\
(.1569)\end{array}$ & $\begin{array}{l}.01 \\
(.6252)\end{array}$ \\
\hline & \multicolumn{5}{|c|}{ Panel (B): Before Closure } \\
\hline GI & $\begin{array}{l}.04 \\
(.537)\end{array}$ & $\begin{array}{l}-.13 \\
(.0132)\end{array}$ & $\begin{array}{l}.13 \\
(.0647)\end{array}$ & $\begin{array}{l}.02 \\
(.7024)\end{array}$ & $\begin{array}{l}.04 \\
(.482)\end{array}$ \\
\hline LI & $\begin{array}{l}.08 \\
(.3437)\end{array}$ & $\begin{array}{l}-.22 \\
(.0071)\end{array}$ & $\begin{array}{l}-.21 \\
(.0571)\end{array}$ & $\begin{array}{l}.03 \\
(.6552)\end{array}$ & $\begin{array}{l}-.04 \\
(.6078)\end{array}$ \\
\hline \multirow[t]{2}{*}{ SI } & $\begin{array}{l}-.01 \\
(.819)\end{array}$ & $\begin{array}{l}-.01 \\
(.8958)\end{array}$ & $\begin{array}{l}-.01 \\
(.8845)\end{array}$ & $\begin{array}{l}.06 \\
(.2796)\end{array}$ & $\begin{array}{l}.03 \\
(.6142)\end{array}$ \\
\hline & \multicolumn{5}{|c|}{ Panel $(C)$ : After Closure } \\
\hline GI & $\begin{array}{l}.19 \\
(.0001)\end{array}$ & $\begin{array}{l}-.02 \\
(.5917)\end{array}$ & $\begin{array}{l}.001 \\
(.8832)\end{array}$ & $\begin{array}{l}.02 \\
(.6143)\end{array}$ & $\begin{array}{l}-.05 \\
(.1217)\end{array}$ \\
\hline LI & $\begin{array}{l}.21 \\
(.0001)\end{array}$ & $\begin{array}{l}.02 \\
(.7577)\end{array}$ & $\begin{array}{l}-.02 \\
(.6321)\end{array}$ & $\begin{array}{l}.01 \\
(.741)\end{array}$ & $\begin{array}{l}-.03 \\
(.4578)\end{array}$ \\
\hline SI & $\begin{array}{l}.16 \\
(.0107)\end{array}$ & $\begin{array}{l}-.01 \\
(.7919)\end{array}$ & $\begin{array}{l}.07 \\
(.1702)\end{array}$ & $\begin{array}{l}.05 \\
(.3476)\end{array}$ & $\begin{array}{l}.01 \\
(.8345)\end{array}$ \\
\hline
\end{tabular}

Notes

- Reported daily returns are in percentages

- $\mathrm{GI}=$ General index that includes all stocks traded in KSE

- $\quad$ LI = Large index that includes only large firms (monthly rebalancing)

- $\quad \mathrm{SI}=$ Small index that includes only small firms (monthly rebalancing)

- Numbers in parentheses are probability values testing the hypothesis that mean = zero

- $\quad$ Before closure $=$ Feb. $1^{\text {st }}, 1984$ to Aug. $1^{\text {st }}, 1990$

- $\quad$ After closure $=$ Sept. $27^{\text {th }}, 1992$ to Dec. $31^{\text {st }}, 2000$

In order to corroborate (and to check) the robustness of the results and due to the two-year obligatory closure of KSE, a structural break test has been conducted to test the stability of parameters for the three indices. The result of this test is contained in table (4)

The probability values of the employed two test statistics confirm a structural break of the return series between the two periods, namely, before and after the obligatory closure of KSE and this is true for both the general and the large firm indices but not for the small firms' index.

The structural break test result necessitates re-estimating the model of table (3) for two distinct sub-periods. Although the test results confirm the stability of the coefficients when employing small firms' index, the model will be re-estimated using the three indices for comparison purposes. The results are contained in table (5). 
Table 3: Results of Regressing Daily Returns on Week Days

\begin{tabular}{lccc}
\hline Dep. Var & GI & LI & SI \\
\hline Sat & .0012 & .0015 & .0008 \\
& $(.0003)$ & $(.0007)$ & $(.0528)$ \\
Sun & -.0007 & -.0009 & -.0001 \\
& $(.035)$ & $(.0522)$ & $(.7781)$ \\
Mon & -.0006 & -.001 & .0003 \\
& $(.1081)$ & $(.0568)$ & $(.2956)$ \\
Tue & .00003 & .0002 & .0005 \\
& $(.9245)$ & $(.579)$ & $(.1566)$ \\
Wed & -.0005 & -.0004 & .0002 \\
& $(.141)$ & $(.3968)$ & $(.6251)$ \\
Adj. R-sq & .005 & .004 & 0 \\
OBS & 3663 & 3663 & 3663 \\
\hline
\end{tabular}

Notes

- $\mathrm{GI}=$ General index that includes all stocks traded at KSE

- $\quad \mathrm{LI}=$ Index that includes only large firms in KSE (monthly rebalancing)

- $\quad \mathrm{SI}=$ Index that includes only small firms in KSE (monthly rebalancing)

- Numbers in parentheses are probability values testing the hypotheses that the coefficient is Zero.

- All errors are adjusted using White's covariance matrix to account for hetroscedastic errors.

Table 4: Chow Structural Break Test

\begin{tabular}{llll}
\hline & GI & LI & SI \\
\hline P (F-statistic) & .0457 & .0279 & .2824 \\
P(Log Likelihood ratio) & .0452 & .0276 & .2811 \\
\hline
\end{tabular}

Notes

- The F-statistic is based on the comparison of the restricted and unrestricted sum of squared residuals.

- The log likelihood ratio statistic is based on the comparison of the restricted and unrestricted maximum of the log likelihood function.

The analysis shows differences between the two sub-periods with respect to the weekend effect. Beforethe-closure period shows no weekend effect as Saturday returns, although positive, are not different from zero. However, after the closure period, Saturday returns become significantly positive. These findings confirm the results obtained by the mean test in tables (2) and (3). All other days' returns are significantly negative at before-the-closure period except when employing the small firms' index. The opposite is true when considering the after closure period as all days' returns, except those of Saturdays', are not different from zero. These results are almost different from those obtained in studies for western stock markets which all report negative returns for the first day of the week and positive returns in the second trading day. The positive Saturday returns are similar to those detected by Alexakis et al (1995) who find positive returns for the first trading day of the week in the Greek stock market. They also document a negative return for the second trading day which is exactly similar to what is observed in KSE. Actually, the two markets might share some similar features as being relatively small emerging markets that include relatively small firms. It is worth to mention that the negative returns of the second trading day are also found in stock markets of France, Australia, Japan, Singapore, and Canada [See Condoyanni et al (1987) and Athanassakes et al (1994)]. ${ }^{6}$ 
Table 5: Diagnostic of the Week End effect

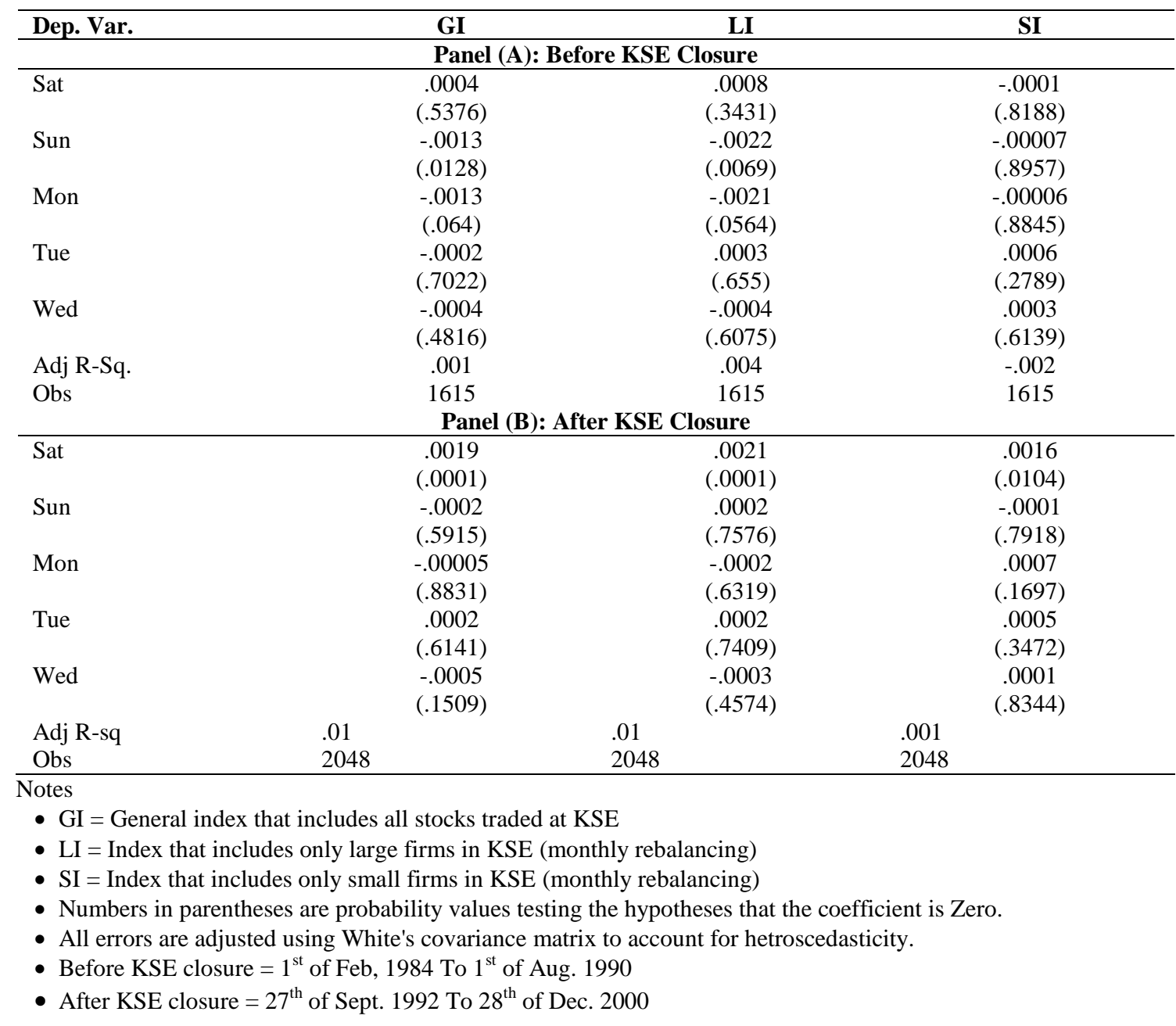

Many researchers have provided some explanations for the weekend effect. Lakonishok and Maberly (1990) hypothesize that as information is reflected in prices with a time lag, most investors process the released information at weekends when they have more time and hence make their portfolio alteration decisions after the last trading day. Along the same lines, other researchers suggest that investors rush their investment decisions at last trading day which create upward pressure on prices and that pressure bids prices up, and in Monday, prices would come to their normal level. To test these conjectures, the relation between last (Wednesday) and first (Saturday) trading days is investigated in the sense that the last trading day conveys certain information that affect investors decisions in the following first trading day. This investigation should shed some light about an appropriate explanation for the observed anomalous phenomena at KSE. The relation is investigated in terms of testing the null hypothesis that Saturday returns are independent of Wednesday returns. This is accomplished by carrying out a proportion test and by constructing a contingency table using the three indices.

Table (6) contains the results of the proportion test by which we investigate the hypothesis that the positive returns in Saturday are independent from those in Wednesday. In other words, what is tested in table (6) is whether or not the price increase in Saturday is independent of the price increase in Wednesday. After calculating the expected frequencies and the test statistic (as it shown in the table), the hypothesis of the relation between 
Wednesday returns and Saturday returns is rejected when considering large and small indices but accepted for the general index. That is, when considering the general index, the probability of a positive Saturday returns seem to be independent from Wednesday returns; while when considering large and small indices, Saturday returns seem to be, on average, dependent on Wednesday returns. This means that the investment decisions of Kuwaiti investors made at the beginning of the week are, on average, not rebuffing to their investment decisions made before the weekend. Differences in results between "GI" and both "LI" and "SI" in table (6) should not be confusing since "LI" and "SI" indices together contain only about $22 \%$ of the listed firm in KSE while "GI" represents the total population of the firms listed in KSE. Our conjecture for the results regarding "LI" and "SI" is that there is an information effect from the last trading day on investors sentiments over the weekend which affects their portfolio decisions on the following first trading day of the week. This flow of information is not exploited by all investors but rather by only the professional investors who usually construct portfolios that are homogenous in certain feature (such as firm size) and hence we should expect those investors to rebalance their portfolios at the beginning of the week as they process some analysis over the weekend and hence tend to reverse those decisions on the first trading day of the week.

\section{January Effect}

It has been documented in the literature that returns in January are considerably higher than returns in other months, especially for small stocks. This phenomenon exists in most developed stock markets as documented by Gultekin and Gultekin (1983). This study also examines January seasonal in KSE. The main acceptable justification for the January effect (tax-selling hypothesis) doesn't apply in KSE since the economy is tax-free.

Table 6: Results of the Proportion Test of Independency of Returns

\begin{tabular}{|c|c|c|c|c|}
\hline \multicolumn{5}{|c|}{ Panel (A) General Index } \\
\hline & $\begin{array}{l}\text { W }(+ \text { ve }) \\
\text { W }(- \text { ve }) \\
\text { Totals } \\
\text { Test-statistic }=.17\end{array}$ & $\begin{array}{l}S(+ \text { ve }) \\
184 \\
222 \\
406\end{array}$ & $\begin{array}{l}\text { S (-ve) } \\
134 \\
172 \\
306\end{array}$ & $\begin{array}{l}\text { Totals } \\
318 \\
394 \\
712\end{array}$ \\
\hline & $\begin{array}{l}\mathrm{W}(+\mathrm{ve}) \\
\mathrm{W}(-\mathrm{ve}) \\
\text { Totals } \\
\text { Test-statistic }=58.74\end{array}$ & $\begin{array}{l}\text { Panel (B } \\
\text { S (+ ve) } \\
187 \\
216 \\
403\end{array}$ & $\begin{array}{l}\text { S (-ve) } \\
145 \\
164 \\
309\end{array}$ & $\begin{array}{l}\text { Totals } \\
332 \\
380 \\
712\end{array}$ \\
\hline & $\begin{array}{l}\mathrm{W}(+\mathrm{ve}) \\
\mathrm{W}(-\mathrm{ve}) \\
\text { Totals } \\
\text { Test-statistic = } 111.7\end{array}$ & $\begin{array}{l}\text { Panel }(C \\
\text { S (+ ve) } \\
290 \\
175 \\
465\end{array}$ & $\begin{array}{l}\text { S (-ve) } \\
131 \\
116 \\
247\end{array}$ & $\begin{array}{l}\text { Totals } \\
421 \\
291 \\
712\end{array}$ \\
\hline$\bullet$ & $\begin{array}{l}\text { W }(+v e) \& W(-v e)=\text { The respective } \\
\mathrm{S}(+\mathrm{ve}) \& \mathrm{~S}(-\mathrm{ve})=\text { The respective p } \\
\text { General Index = Includes all firms tra } \\
\text { Large index = includes large firms in } \\
\text { Small Index = includes small firms ir } \\
\text { With } 1 \mathrm{df}[\text { calculated as }(\mathrm{c}-1)(\mathrm{r}-1) \text { an } \\
\text { rows)], the tabulated value of Chi-sq }\end{array}$ & $\begin{array}{l}\text { positive ar } \\
\text { sitive and } \\
\text { ded in KS } \\
\mathrm{KSE} \text { (mor } \\
\mathrm{KSE} \text { (mo } \\
\text { "c" is the } \\
\text { are with } 5\end{array}$ & $\begin{array}{l}\text { e returns } \\
\text { returns in } \\
\text { ing) } \\
\text { cing) } \\
\text { olumns w } \\
\text { ce level is }\end{array}$ & umber of \\
\hline
\end{tabular}


Table (7) shows two types of tests regarding the January effect. First is investigating the average returns of both January and other months. Although January (other months') returns are negative (positive), they are statistically insignificant. Second, the mean difference test investigates the difference between January returns and other months' returns. As it appears in the table, the results of the mean difference confirm the in-existence of January effect in KSE as the difference between January returns and those of other months is statistically insignificant ${ }^{7}$. In contrast to what has been documented in developed stock markets which confirms the idea that emerging markets provide higher degree of segmentation than do developed markets, the insignificance of the January effect is somewhat expected in light of the study of Claessens and Dasgupta (1995) who find no evidence of January effect in about twenty emerging markets.

Table 7: Monthly Mean Returns ${ }^{8}$

\begin{tabular}{lccc}
\hline & GI & LI & SI \\
\hline January & -1.91 & -1.89 & -.24 \\
& $(.2035)$ & $(.3795)$ & $(.4919)$ \\
All Months & .24 & .33 & 1.04 \\
& $(.6595)$ & $(.6329)$ & $(.0624)$ \\
Mean Difference & -.0216 & -.0222 & -.0187 \\
& $(.253)$ & $(.347)$ & $(.32)$ \\
\hline
\end{tabular}

Notes

- All returns are in percentage form

- $\quad \mathrm{GI}=$ Index that includes all listed firms in KSE

- $\quad \mathrm{LI}=$ Index that includes large firms in KSE (monthly rebalancing)

- $\quad \mathrm{SI}=$ Index that includes small firms in KSE (monthly rebalancing)

- Numbers in parenthesis are probability values testing the hypothesis that the coefficient is zero

\section{3. Summer Effect}

Researchers often refer to an old market wisdom that relate to the behavior of investors every year. This wisdom is represented by what is usually cited by the financial press in western markets as "Sell in May and go away". This common saying suppose to signals a start of a bear market every year at the month of May as investors tend to sell their stocks for cash to spend on their vacations. This common saying appears to apply in Kuwait as most investors (and most people) in Kuwait spend their vacations in summer out of the country. Therefore, persistence in stock returns over months of the year is investigated to explore any seasonal trends.

Interestingly, and opposite to our predictions, Figure (1) shows the average monthly returns over the period 19842000 for the general index (GI) that includes all stocks in KSE. We can notice that stocks returns (monthly data) tend to be higher during the summer time which contradicts the market wisdom mentioned earlier. The same graph is repeated for both the small and the large portfolios during the same period (1984-2000). 

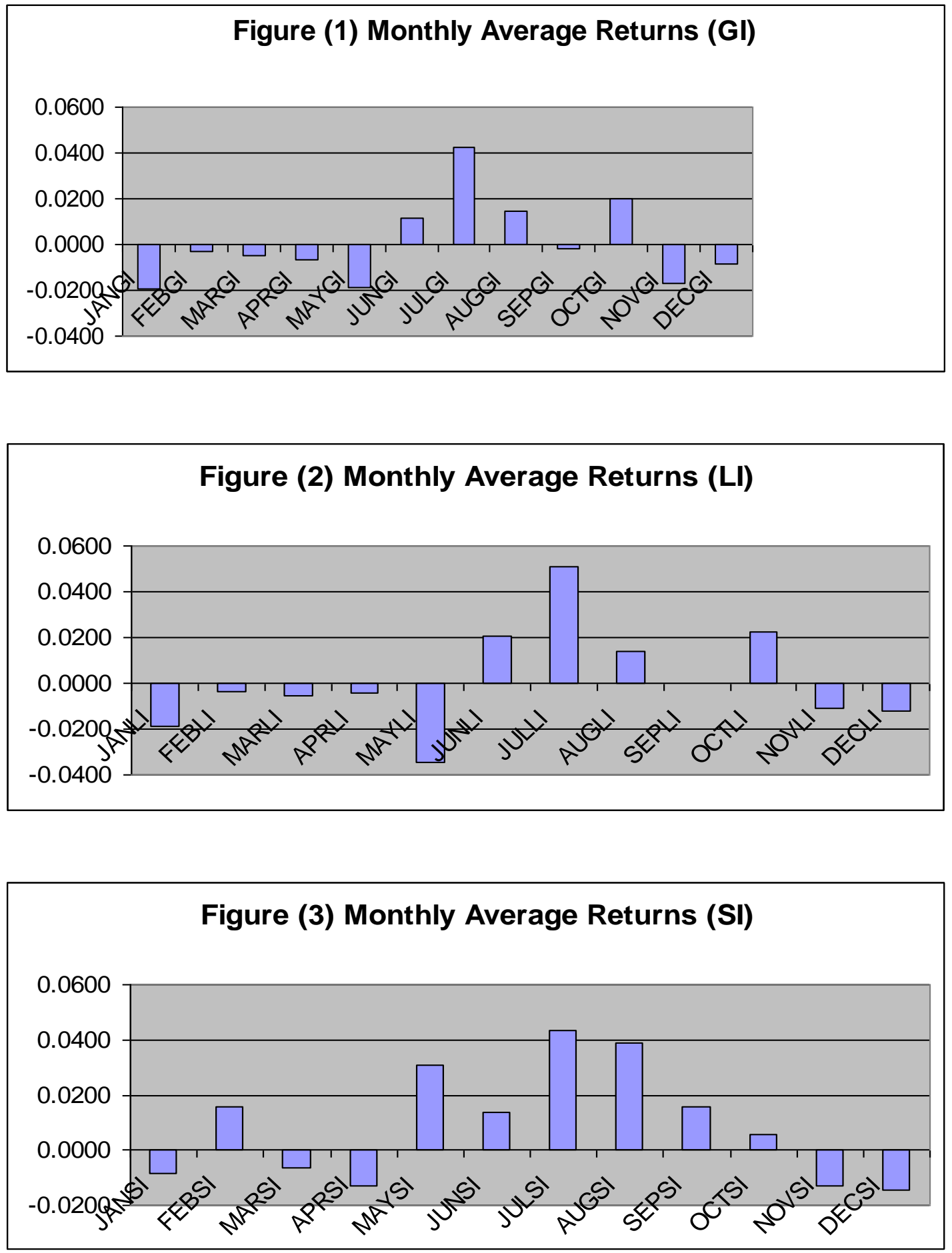

It is apparent that returns during summer time, on average, tend to be higher even after considering the large and the small portfolios (indices). The month of May has positive returns only when considering the small portfolio. Graphs usually represent informal tests. Hence, a regression model is to be formulated to investigate if there is a summer anomaly in KSE. 
The regression model takes the form of $\mathrm{R}_{\mathrm{i}}=\mathrm{f}$ (dummy variable) $+\mathrm{e}$, where the dummy variable takes the value of " 1 " for the months from October to May and "zero" otherwise; $\mathrm{R}_{\mathrm{i}}$ is the monthly returns of the specified index. Results of this test are contained in table (8). The results confirm the existence of the summer effect in KSE but in another (and opposite) setting than what is documented in western markets (see for example Bouman and Jacobsen, 1999). Specifically, summer months (May to September) in KSE tend to experience higher returns than those of other months of the year (October to April). This results is robust to the size of the firm as using both indices employed in the study don't change the obtained result.

\section{Table 8: the Summer Effect}

\begin{tabular}{llll}
\hline & GI & LI & SI \\
\hline The Dummy Variable & -.02941 & -.03593 & -.03041 \\
& $(.018)$ & $(.0213)$ & $(.0169)$ \\
Adjusted R-Square & .03 & .0285 & .033 \\
\hline
\end{tabular}

Notes

- $\mathrm{GI}=$ General index that includes all stocks traded at KSE

- $\quad \mathrm{LI}=$ Index that includes only large firms in KSE (monthly rebalancing)

- $\quad \mathrm{SI}=$ Index that includes only small firms in KSE (monthly rebalancing)

- Numbers in parentheses are probability values testing the hypotheses that the coefficient is Zero

The dummy coefficient is negative and significantly different from zero (as indicated by the p-value) in all the three models shown in table (8). This result comes in contrast with many studies who document the opposite (Gultekin and Gultekin, 1983; Rozeff and Kinney, 1976). Also, this result confirm the conjecture that every market has its own characteristics and that emerging markets are distinct in their institutional features which should have its effects on the results. Furthermore, the result comes in contrast to the view of many Kuwait investors who claim that summer months represent a bear market since most investors take their vacations during summer.

\section{Conclusion and Discussion}

This paper examines the sample distribution of the daily returns in order to explore the seasonal anomalies in KSE using a uniform data set and methodology. The evidence described so far provides (unlike what has been documented in developed markets) pungent support for the idea that rates of return are highest in Saturday (first trading day) and lowest in Sunday (second trading day) at KSE. Also, this study documents no consistent behavior of returns over months of the year. Although the study finds some consistent negative returns, these are insignificant and hence are statistically not different from zero. In addition, the study finds that, contrary to what is documented in developed stock markets, returns during summer months (May-September) are higher than returns in other months of the year (October-April). The results obtained are robust to the methodology used and to both sub-periods investigated and the constructed size-portfolios.

Although the nature of the obtained data compel the study to be exploratory in the sense that more detailed data (which are not available) has to be obtained and analyzed in order to explain the observed phenomena, there is some room for few explanations. One compelling argument ${ }^{9}$ relates to the nature of investors' mentality in KSE. That is, most investors in KSE seem to double think in their investment decisions over the weekend. Unlike the situation in developed markets, very little news are released over the weekend at KSE and on top of that, most investors don't pay attention to these news as they think that these news are not informative. As they sense nothing momentous has occurred at the previous week, investors tend to time their purchases at the first trading day following the weekend and hence their propensity to buy is higher than their propensity to sell in Saturdays ${ }^{10}$. At the same time, most investors think that their purchases have to be reversed within the next two days. Hence, those investors, and in order to capitalize on their marginal profits, rush to sell what has been bought in Saturday to. Another rational explanation is the risk factor. That is, influential investors in KSE usually, by a bit collusion, bid 
stock prices up in Saturday, speculating that they find buyers to these stocks on Sunday in which they dump the market with stocks. Apparently, this strategy entails higher risk exposure.

Regarding the difference in results between KSE and other international stock markets, one has to notice three main institutional differences. First is the relatively smaller size of firms traded in KSE and these firms are thinly traded (Al-loughani, 1995). Second is that all firms as well as investors in KSE don't pay taxes. Third, KSE market as an emerging market is still developing institutionally. Accordingly, investors' sentiment and risk aversion are altered due to these developments

For January effect, Kuwait has free-tax economy and hence tax-selling experienced in other stock markets (which sought to cause January effect) is absent in Kuwait and therefore, one should not expect turn-of-the-year seasonal. On the other hand, it seems that many influential investors manage their investments in summer in a certain way that causes returns of summer months (May-September) to be higher than those of other months of the year ${ }^{11}$. One implication has to be mentioned and we quit. Usually, when certain regularities exist in an equity market, one would wonder if these regularities can be impeded in an investment strategy. That is, how investors in KSE would behave to deal with such phenomena. The concept of stock market efficiency is contingent upon information availability to all investors, which hinders any exploitation by part of the investment community. Kuwaiti investors don't seem to behave according to the news released over the weekend about firms. Although the commission costs should be considered before full exploitation of the anomaly, the conventional wisdom dictates that investors should delay their stocks' sale from Wednesday, for example, to Saturday, and repurchase or make their purchase decisions on Sunday.

\section{References}

1. Agrawal, A. and K. Tandom, (1994), "Anomalies or illusions? Evidence from Stock Markets in Eighteen Countries", Journal of International Money and Finance, V(13), 83-106.

2. Al-loughani, N., (1995). Random Walk in Thinly Traded Stock Markets: The Case of Kuwait. Arab Journal of Administrative Sciences 3: 189-210.

3. Athanassakos, G. and M. Robinson, (1994), "The Day of the Week Anomaly: The Toronto Stock Exchange Experience", Journal of Business Finance and Accounting, V(21), 833-856.

4. Ball, R. and J. Bowers, (1986), "Daily Seasonals in Equity and Fixed-Interest Returns: Australian Evidence and Tests of Plausible Hypotheses", Working Paper, Australian Graduate School of Management.

5. Banz, R. (1981), "The Relationship Between Returns and Market Value of Common Stock", Journal of Financial Economics, V(9), 3-18.

6. Barry, C. and S. Brown (1985), "Differential Information and Security Market Equilibrium", Journal of Financial and Quantitative Analysis, V(20), 407-422.

7. $\quad$ Bekaert, G., and C. Harvey, (2003), "Emerging Markets finance", Journal of Empirical Finance, V(10), 355

8. $\quad$ Black, F. (1986), "Noise”, Journal of Finance, V.(41), 529-543.

9. Jacobsen, B., and Bouman, S., (2002), “The Halloween Indicator, 'Sell in May and Go Away': Another Puzzle", The American Economic Review, V(92), No (5), 1618-1635

10. $\quad$ Branch, B., (1977), "A Tax Loss Trading Rule", Journal of Business, V(50), 198-207.

11. Butler, K., and S. Malaikah, (1992), "Efficiency and Inefficiency in Thinly Traded Stock Market: Kuwait and Saudi Arabia", Journal of Banking and Finance, V(16), 197-210.

12. Claessens, S., S. Dasgupta, and J. Glen (1995), "Return Behavior in Emerging StockMarkets", World Bank Economic Review, 131-151.

13. Condoyanni, L., and O'Hanlon, J., and C. Ward, (1987), "Day of the Week Effects on Stock Returns: International Evidence", Journal of Business Finance \& Accounting, V(14), 159-174.

14. Cross, F., (1973), "The Behavior of Stock Prices on Fridays and Mondays", Financial Analyst Journal, Nov-Dec, 67-69.

15. French, K., (1980), "Stock Returns and the Weekend Effect", Journal of Financial Economics, V(8), 55-70.

16. Gibbons, M. and P. Hess, (1981), "Day of the Week Effect and Asset Returns", Journal of Business, V(54), 578-596. 
17. Gultekin, M. and N. Gultekin, (1983), "Stock Market Seasonality: International Evidence", Journal of Financial Economics, V(12), 469-481.

18. Jaffe, J., R. Westerfield, and C. Ma, (1989), "A Twist on the Monday Effect in Stock Prices: Evidence from the US and Foreign Stock Markets, Journal of Banking and Finance, V(13), 641-650.

19. Keim, D. and R. Stambaugh, (1984), "A Further Investigation of the Weekend Effect in Stock Returns", Journal of Finance, V(39), 819-835.

20. Lo, A. Lo, A., and Mackinlay, (1997), The Econometrics of Financial Markets, Princeton: Princeton University Press.

21. Reinganum, M. (1981), "Misspecification of Capital Asset pricing: Empirical Anomalies Based on Earnings Yields and Market Values, Journal of Financial Economics, V(9), 19-46.

22. Rozeff, M. and W. Kinney, (1976), "Capital Market Seasonality: The Case of Stock Returns", Journal of Financial Economics, V(3), 379-402.

23. Tinic, S. and R. West, (1984), "Risk and Returns: January vs. the Rest of the Year", Journal of Financial Economics, V(13), 561-574.

24. White, H. (1980), "A Hetroscadasticity-Consistent Covariance Matrix Estimator and Direct Test for Hetroscedasticity”, Econometrica, V. 48, 817-838.

\section{Endnotes}

${ }^{1}$ It is worth noting here that tax-loss selling is irrelevant in KSE since one of the distinct feature of Kuwaiti economy is that it is a tax-free economy.

${ }^{2} \mathrm{KSE}$ annual report, different issues.

${ }^{3}$ An interesting article on the importance of noise in security returns would be that of Fisher Black's (1986) presidential address.

${ }^{4}$ Recently, a rule has been issued that halts trading of securities whose firms delay their annual (or quarterly) financial statements more than 3 months.

${ }^{5}$ Kuwait was occupied by Iraq on $2^{\text {nd }}$ of Aug, 1990 but was liberated at $26^{\text {th }}$ of Feb, 1991. Definitely, resuming trading just right after liberation was not a priority and KSE reopening came after rebuilding the country.

${ }^{6}$ Some researchers, for example Alexakis et al (1995), have employed a GARCH model to account for the changing variance over time. The same analysis in tables $(2,3$, and 4$)$ was carried out but using GARCH model. Since almost the same results were obtained as in tables (2,3, and 4) regarding the positive returns on Saturday and the negative returns on Sunday, the results are not reported for brevity reasons.

${ }^{7}$ A regression test also is run to investigate the relation between returns and January returns but the results are not different from those obtained in table (7) hence the results are not reported for brevity reasons.

${ }^{8}$ The monthly returns are calculated based on the closing price of the month.

${ }^{9}$ This explanation was brought up by many investors who were asked by the researcher.

${ }^{10}$ Due to data unavailability, we can not claim that there is a day of the week effect in processing information.

${ }^{11}$ Many information are needed to investigate this conjecture but unfortunately are unavailable 